\title{
External Validation and Comparison of Simple Tools to Screen for Nonalcoholic Fatty Liver disease in Chinese community population
}

\author{
Liuxin Zhang \\ Nanjing Medical University \\ Min Wang \\ Nanjing Medical University \\ Minxian Wang \\ Nanjing Medical University \\ Ru Zhang \\ Nanjing Medical University \\ Hongliang Wang \\ Mofan West Road Community Health Service Center \\ Wei Zhang \\ Shanghai Cancer Institute \\ Yajie Ding \\ Nanjing Medical University \\ Jie Wang ( $\nabla$ wangjienjmu@126.com ) \\ Nanjing Medical University https://orcid.org/0000-0001-7159-5839
}

\section{Research}

Keywords: Nonalcoholic fatty liver disease (NAFLD), Non-invasive diagnosis, Fatty liver index (FLI), Fatty liver disease index (FLD), Zhejiang University index (ZJU), Lipid accumulation product (LAP), Regression formula of controlled attenuation parameter (CAP), Waist-to-height ratio (WHtR), Triglyceride and glucose index (TyG), Visceral adiposity index (VAI)

Posted Date: November 25th, 2020

DOI: https://doi.org/10.21203/rs.3.rs-112991/v1

License: (a) This work is licensed under a Creative Commons Attribution 4.0 International License. Read Full License 


\section{Abstract}

Background: Various non-invasive tools based on anthropometric indicators, blood lipids, and liver enzymes, etc. have been developed to screen for nonalcoholic fatty liver disease (NAFLD), with different diagnostic performance and cutoff values among studies. We aimed to validate and compare eight NAFLD-related models developed by simple indicators and to define their cut-off values in Chinese community population.

Methods: A cross-sectional study was conducted in a health examination cohort of 3259 people. NAFLD was diagnosed by ultrasonography. General, anthropometric and biochemical data were collected. Fatty liver index (FLI), fatty liver disease index (FLD), Zhejiang University index (ZJU), lipid accumulation product (LAP), regression formula of controlled attenuation parameter (CAP), waist-to-height ratio (WHtR), triglyceride and glucose index (TyG), and visceral adiposity index (VAI) were calculated. The accuracy and cut-off points to detect NAFLD were evaluated by area under the receiver operator characteristic curve (AUROC) and the maximum Youden index analysis, respectively. A head-to-head comparison between these models and Decision Curve Analysis were conducted.

Results: All of eight models are significant in different degrees of NAFLD. In 8 noninvasive diagnostic models of NAFLD, AUCs of FLI and FLD for NAFLD were higher than those of other models in the whole (0.852 and 0.852), male (0.826 and 0.824), and female (0.897 and 0.888) population, respectively. Decision Curve Analysis showed that FLI, FLD and ZJU have higher net benefit to screen for NAFLD compared to other models. The cut-off points of FLI and FLD for NAFLD were different in the total (20.6 and 28.7), male (25.3 and 29.0), and female (8.4 and 26.1) population.

Conclusions: FLI and FLD could be the most accurate and applicable of 8 models for the noninvasive diagnosis of NAFLD in both male and female groups.

\section{Introduction}

Nonalcoholic fatty liver disease (NAFLD) is becoming increasingly prevalent, affecting more than one-quarter adults in the world, with the prevalence of $20.09 \%$ in China [1] .The spectrum of NAFLD covers from simple steatosis or nonalcoholic fatty liver (NAFL) to nonalcoholic steatohepatitis (NASH). It may progress to fibrosis, leading to cirrhosis and hepatocellular carcinoma [2]. NAFLD has imposed a severe burden on the whole world [3-5].

The golden standard for diagnosis of NAFLD is the liver biopsy but it may cause severe complications, such as bleeding, pain and death [6]. Imaging techniques such as ultrasonography, computed tomography (CT), Magnetic Resonance Imaging (MRI) and magnetic resonance spectroscopy as noninvasive approaches are well studied to detect NAFLD [7]. But the costs associated with imaging techniques limit its widespread use for large scale screening of asymptomatic individuals like community population. Moreover, the increasing incidence of NAFLD calls for practical and cost-effective screening and monitoring. Predictive models based on clinical and laboratory biomarkers are prevalent in recent years [8]. The practical advantages of biomarkers include their high applicability, their good interlaboratory reproducibility, and their potential widespread availability.

A variety of noninvasive models based on biomarkers have been developed for NAFLD screening in the past two decades [8]. Current NAFLD-related models including fatty liver index (FLI), fatty liver disease index (FLD), Zhejiang University index (ZJU), lipid accumulation product (LAP), regression formula of controlled attenuation parameter (CAP), waist-to-height ratio (WHtR), triglyceride and glucose index (TyG), and visceral adiposity index (VAI) were well documented [9-16]. However, the performance and cut-off values of these models are varied by region and race. For example, the cut-off values of FLI were $<30$ and $>60$ for total population to rule out and in NAFLD in the primary study [10], and it was $<10$ for female and $<25$ for male to rule out NAFLD, $\geq 20$ for female and $\geq 35$ for male to rule in NAFLD in a validation study in Taiwan [17]. Although some of the models have been validated independently, their diagnostic 
performances are difficult to compare, as they have been designed and validated against different standards (liver biopsy, ultrasonography, or magnetic resonance spectroscopy) $[8,18]$.

This study aimed to validate and compare the current noninvasive models developed by simple biomarkers, so as to find suitable screening methods and determine the cut-off values for NAFLD in the eastern Chinese community population.

\section{Methods}

\section{Study population}

We conducted a cross-sectional study. Participants were from a community in Nanjing, eastern China who received health check-up services from July to September 2018. All participants have signed informed consents. The study design was approved by the Ethics Committee of Nanjing Medical University and in accordance with the ethical standards in the Declaration of Helsinki.

The exclusion criteria of this study were subjects who: 1) had uncompleted clinical data; 2) had a significant alcoholic consumption (men > $140 \mathrm{~g}$ or women $>70 \mathrm{~g}$ per week in the past 12 months); 3 ) had viral/autoimmune hepatitis, druginduced liver damage or other liver diseases; 4) have undergone gastrointestinal surgery; 5) had a history of mental disorders.

\section{Measurement}

All participants received physical examination, laboratory examination and upper abdominal ultrasonography. Weight, height, and waist circumstance (WC) were all measured wearing minimal clothing and without socks by the same nurses and same machine. Body mass index (BMI) was calculated as: BMI = weight $(\mathrm{kg}) /$ height $(\mathrm{m})^{2}$. Whole blood samples were collected after 10-hour overnight fasting and serum samples were separated for immediate analysis. Fasting plasma glucose (FPG), triglycerides (TG), total cholesterol (TC), high-density lipoprotein cholesterol (HDL-C), low-density lipoprotein cholesterol (LDL-C), alanine aminotransferase (ALT), aspartate aminotransferase (AST) and Yglutamyl transferase (GGT) were measured by a biochemical analyzer (Mindray BS-860, China). The abdominal ultrasonography was performed by the same two experienced technicians and a LOGIQ-E9 ultrasound system (General Electric Healthcare, Milwaukee, WI, USA).

\section{Diagnosis of NAFLD}

The diagnosis of NAFLD was in accord with the Guidelines for Diagnosis and Treatment of NAFLD issued by Fatty Liver and Alcoholic Liver Disease Study Group of the Chinese Liver Disease Association in 2010 and the updated one in 2018 [19, 20], including: (1) alcohol consumption < $140 \mathrm{~g} / \mathrm{wk}$ for male adults and < $70 \mathrm{~g} / \mathrm{wk}$ for female adults; (2) absence of viral hepatitis (HBV/HCV), hepatolenticular degeneration, autoimmune diseases, a history of total parenteral nutrition, or intake of any hepatotoxic drugs (e.g. tamoxifen, amiodarone, sodium valproate, methotrexate, and glucocorticoid); (3) liver fatty infiltration by ultrasonographic examination, or metabolic syndrome presented elevated serum liver enzymes (>6 months).

\section{Calculation of predictive models}

Eight models were validated and compared in this study. The formulas of models were checked by tracing back to the original literature (Table 1). TG in FLI and TyG; and FPG in TyG are in mg/dL. TG in FLD, LAP and VAl; FPG in ZJU; and HDL-C in VAl are all in mmol/L. WC and height are in centimeter. BMI is in $\mathrm{kg} / \mathrm{m}^{2}$ and AST, ALT, and GGT are in IU/L. 


\begin{tabular}{|c|c|c|c|}
\hline Model & Full name & $\begin{array}{l}\text { Country, } \\
\text { year }\end{array}$ & Formula \\
\hline $\begin{array}{l}\text { FLI } \\
{[10]}\end{array}$ & Fatty Liver Index & $\begin{array}{l}\text { Italy, } \\
2006\end{array}$ & $\begin{array}{l}\mathrm{FLI}=(\mathrm{e} 0.953 \times \ln \mathrm{TG}+0.139 \times \mathrm{BMI}+0.718 \times \ln (\mathrm{GGT})+0.053 \times \mathrm{WC} \\
-15.745) /(1+\mathrm{e} 0.953 \times \ln \mathrm{TG}+0.139 \times \mathrm{BMI}+0.718 \times \ln (\mathrm{GGT})+ \\
0.053 \times \mathrm{WC}-15.745) \times 100\end{array}$ \\
\hline $\begin{array}{l}\text { FLD } \\
{[14]}\end{array}$ & $\begin{array}{l}\text { Fatty liver disease } \\
\text { index }\end{array}$ & $\begin{array}{l}\text { China, } \\
2013\end{array}$ & $\begin{array}{l}\text { FLD index }=\mathrm{BMI}+\mathrm{TG}+3(\mathrm{ALT} / \mathrm{AST} \text { ratio })+2 \mathrm{HG} \text { (presence of } \mathrm{HG} \text {, } \\
\mathrm{HG}=1 ; \text { absence of } \mathrm{HG}, \mathrm{HG}=0)\end{array}$ \\
\hline ZJU & $\begin{array}{l}\text { Zhejiang University } \\
\text { index }\end{array}$ & $\begin{array}{l}\text { China, } \\
2015\end{array}$ & ZJU index $=\mathrm{BMI}+\mathrm{FPG}+\mathrm{TG}+3 \mathrm{ALT} / \mathrm{AST}$ ratio $+2($ if female $)$ \\
\hline \multirow{2}{*}{$\begin{array}{l}\text { LAP } \\
{[12]}\end{array}$} & \multirow{2}{*}{$\begin{array}{l}\text { Lipid accumulation } \\
\text { product }\end{array}$} & \multirow{2}{*}{$\begin{array}{l}\text { Italy, } \\
2010\end{array}$} & $\mathrm{LAP}($ male $)=(\mathrm{WC}-65) \times \mathrm{TG}$ \\
\hline & & & LAP $($ female $)=(W C-58) \times T G$ \\
\hline $\begin{array}{l}\text { CAP } \\
{[16]}\end{array}$ & $\begin{array}{l}\text { Regression formula of } \\
\text { controlled attenuation } \\
\text { parameter }\end{array}$ & $\begin{array}{l}\text { China, } \\
2018\end{array}$ & $\mathrm{CAP}=113.163+0.252 \times \mathrm{ALT}+6.316 \times \mathrm{BMI}$ \\
\hline $\begin{array}{l}\text { WHtR } \\
{[9]}\end{array}$ & Waist-to-Height Ratio & $\begin{array}{l}\text { Japan, } \\
1995\end{array}$ & WHtR $=$ WC $/$ height $\times 100$ \\
\hline $\begin{array}{l}\text { TyG } \\
{[11]}\end{array}$ & $\begin{array}{l}\text { Triglyceride and } \\
\text { glucose index }\end{array}$ & $\begin{array}{l}\text { Mexico, } \\
2008\end{array}$ & $\operatorname{TyG}=\ln [(T G \times F P G) / 2]$ \\
\hline \multirow[t]{2}{*}{$\begin{array}{l}\text { VAl } \\
{[13]}\end{array}$} & \multirow[t]{2}{*}{ Visceral adiposity index } & \multirow[t]{2}{*}{$\begin{array}{l}\text { Italy, } \\
2012\end{array}$} & $\begin{array}{l}\operatorname{VAl}(\text { male })=(\mathrm{WC} /(39.68+(1.88 \times \mathrm{BMI}))) \times(\mathrm{TG} / 1.03) \times(1.31 / \\
\mathrm{HDL}-\mathrm{C})\end{array}$ \\
\hline & & & $\begin{array}{l}\text { VAl }(\text { female })=(\text { WC } /(39.58+(1.89 \times \text { BMI }))) \times(T G / 0.81) \times(1.52 / \\
\text { HDL-C })\end{array}$ \\
\hline $\begin{array}{l}\text { Abbrev } \\
\text { circum } \\
\text { glucos } \\
\text { BP, blo }\end{array}$ & $\begin{array}{l}\text { tions: TG, triglyceride; BM } \\
\text { rence; ALT, alanine amino } \\
\text { TB, total bilirubin; TC, tota } \\
\text { pressure; platelet count. }\end{array}$ & ody mas & $\begin{array}{l}\text { index; GGT, gamma-glutamyl transpeptidase; WC, waist } \\
\text { AST, aspartic transaminase; HG, hyperglycemia; FPG, fasting plasma } \\
\text { DM, diabetes mellitus; HDL-C, high-density lipoprotein cholesterol; }\end{array}$ \\
\hline
\end{tabular}

\section{Statistical analysis}

Continuous variables are presented as mean \pm standard deviation or median (interquartile range), and categorical variables are presented as numbers and percentages. The Student's t test or Mann-Whitney U test for continuous variables, and chi-squared test or Kruskal-Wallis test for categorical variables were used to compare the parameters between NAFLD and non-NAFLD groups. Receiver operating characteristic (ROC) curves of models were developed to predict the presence of NAFLD. Comparisons of the areas under receiver operating characteristic (AUC) curves between every two models were performed, using the method of DeLong et al. [21]. Decision Curve Analysis (DCA) was also conducted to compare these models. Youden index and the discriminant ability at each cut-off value for NAFLD-related models were used to determine the optimal cut-off value to diagnose NAFLD in total, male and female population. Descriptive analyses, correlation analyses and ROC analyses were performed using SPSS (version 23.0, IBM Corp., Chicago, IL, USA). The ROC comparison of NAFLD-related models using method of DeLong et al. was performed by MedCalc (version 11.4.2.0, MedCalc Inc., Mariakerke, Belgium) and DCA was performed by R software (version 3.6.2, https://www.r-project.org/). A two-sided $P<0.05$ was considered statistically significant.

\section{Results}

\section{Characteristics of the study population}


After excluding 391 participants according to our exclusion criteria (significant alcohol consumption [ $\mathrm{n}=257]$, positive hepatitis $C$ virus [ $n=19]$, use of medication associated with fatty liver [ $n=103$ ] and with mental disorders [ $=12]$ ), a total of 3259 subjects were included in the analysis. As shown in Table 2, overall characteristics of the population were depicted and eight models namely FLI, FLD, ZJU, TyG, CAP, LAP, WHtR and VAI were also displayed. Seventy three percent of the study population was male, and mean age of participants was $40.59 \pm 9.30$ years. NAFLD was present in 1169 of 3259 participants (35.9\%). Patients with mild fatty liver accounted for $69.8 \%(n=816)$; moderate accounted for $24.0 \%(n=280)$ and severe accounted for $6.2 \%(n=73)$. NAFLD group had higher levels of NAFLD-related indexes than non-NAFLD group. 
Table 2

Characteristics of the study population and comparison between subjects with and without NAFLD

\begin{tabular}{|c|c|c|c|c|c|}
\hline Variables & $\begin{array}{l}\text { All participants } \\
(n=3259)\end{array}$ & $\begin{array}{l}\text { Non-NAFLD } \\
(n=2090)\end{array}$ & $\begin{array}{l}\text { NAFLD } \\
(n=1169)\end{array}$ & $\chi^{2} / t / Z$ & $P$ \\
\hline Male (n, \%) & $2387(73.2)$ & $1378(65.9)$ & 1009 (86.3) & 158.887 & $<0.001^{a}$ \\
\hline Age(years) & $40.59 \pm 9.30$ & $39.61 \pm 9.24$ & $42.34 \pm 9.15$ & -8.1 & $<0.001^{b}$ \\
\hline $\mathrm{WC}(\mathrm{cm})$ & $83.01 \pm 9.47$ & $79.65 \pm 8.55$ & $89.03 \pm 7.93$ & -31.48 & $<0.001^{b}$ \\
\hline $\mathrm{BMI}\left(\mathrm{kg} / \mathrm{m}^{2}\right)$ & $23.46 \pm 2.97$ & $22.37 \pm 2.61$ & $25.42 \pm 2.54$ & -32.28 & $<0.001^{b}$ \\
\hline SBP(mmHg) & $125.45 \pm 15.34$ & $122.37 \pm 14.31$ & $130.97 \pm 15.59$ & -15.54 & $<0.001^{b}$ \\
\hline $\mathrm{DBP}(\mathrm{mmHg})$ & $75.88 \pm 10.46$ & $73.73 \pm 9.66$ & $79.73 \pm 10.74$ & -15.85 & $<0.001^{b}$ \\
\hline $\mathrm{TC}(\mathrm{mmol} / \mathrm{L})$ & $4.60 \pm 0.86$ & $4.49 \pm 0.81$ & $4.79 \pm 0.90$ & -9.44 & $<0.001^{b}$ \\
\hline $\mathrm{TG}(\mathrm{mmol} / \mathrm{L})$ & $1.16(0.84,1.70)$ & $0.99(0.75,1.33)$ & $1.66(1.19,2.28)$ & -26.61 & $<0.001^{\mathrm{c}}$ \\
\hline TBIL(mmol/L) & $13.86(10.87,17.84)$ & $13.92(10.97,18.00)$ & $13.73(10.76,17.66)$ & -1.16 & $0.248^{c}$ \\
\hline $\mathrm{DBIL}(\mathrm{mmol} / \mathrm{L})$ & $4.13(3.35,5.15)$ & $4.22(3.37,5.27)$ & $4.01(3.29,5.00)$ & -3.30 & $0.001^{c}$ \\
\hline HDL-C(mmol/L) & $1.24 \pm 0.32$ & $1.33 \pm 0.33$ & $1.08 \pm 0.25$ & 24.11 & $<0.001^{b}$ \\
\hline LDL-C(mmol/L) & $2.70 \pm 0.74$ & $2.64 \pm 0.71$ & $2.81 \pm 0.78$ & -6.04 & $<0.001^{b}$ \\
\hline ALT (IU/L) & $19(14,29)$ & $16(12,23)$ & $26(19,38)$ & -23.33 & $<0.001^{c}$ \\
\hline AST (IU/L) & $19(16,23)$ & $18(15,21)$ & $21(17,25)$ & -14.83 & $<0.001^{c}$ \\
\hline GGT (IU/L) & $19(13,31)$ & $16(12,24)$ & $29(19,42)$ & -24.08 & $<0.001^{c}$ \\
\hline $\operatorname{Scr}(\mathrm{mmol} / \mathrm{L})$ & $66.94 \pm 13.29$ & $65.69 \pm 13.44$ & $69.04 \pm 12.76$ & -6.96 & $<0.001^{b}$ \\
\hline FPG(mmol/L) & $4.75(4.48,5.05)$ & $4.70(4.45,4.97)$ & $4.85(4.55,5.21)$ & -9.16 & $<0.001^{c}$ \\
\hline FLI & $17.30(6.79,38.74)$ & $9.86(4.58,20.60)$ & $41.27(23.94,60.09)$ & -33.39 & $<0.001^{c}$ \\
\hline FLD & $28.34 \pm 4.29$ & $26.54 \pm 3.46$ & $31.58 \pm 3.68$ & -38.97 & $<0.001^{b}$ \\
\hline ZJU & $33.68 \pm 4.22$ & $31.95 \pm 3.36$ & $36.79 \pm 3.80$ & -36.35 & $<0.001^{b}$ \\
\hline
\end{tabular}

Data are mean \pm standard deviation or median (interquartile range) for continuous variables; $P$ values present comparisons between NAFLD patients and non-NAFLD subjects.

${ }^{\mathrm{a}}$ chi-squared test, ${ }^{\mathrm{b}}$ independent-samples $\mathrm{T}$ test, ${ }^{\mathrm{C}}$ Mann-Whitney $\mathrm{U}$ test.

Abbreviations: NAFLD, nonalcoholic fatty liver disease; WC, waist circumference; BMI, body mass index; SBP, systolic blood pressure; DBP, diastolic blood pressure; TC, total cholesterol; TG, triglyceride; TBIL, total bilirubin; DBIL, direct bilirubin; HDL-C, high-density lipoprotein cholesterol; LDL-C, low-density lipoprotein cholesterol; ALT, alanine aminotransferase; AST, aspartic transaminase; GGT, gamma-glutamyl transpeptidase; Scr, serum creatinine; FPG, fasting plasma glucose; platelet count; FLI, fatty liver index; FLD, fatty liver disease index; ZJU, Zhejiang University index; TyG, triglyceride and glucose index; CAP, controlled attenuation parameter; LAP, lipid accumulation product; WHtR, waist-to-height ratio; VAl, visceral adiposity index. 


\begin{tabular}{|c|c|c|c|c|c|}
\hline Variables & $\begin{array}{l}\text { All participants } \\
(n=3259)\end{array}$ & $\begin{array}{l}\text { Non-NAFLD } \\
(n=2090)\end{array}$ & $\begin{array}{l}\text { NAFLD } \\
(n=1169)\end{array}$ & $x^{2} / t / Z$ & $P$ \\
\hline TyG & $8.89 \pm 2.97$ & $7.87 \pm 2.48$ & $10.70 \pm 2.93$ & -27.88 & $<0.001^{b}$ \\
\hline CAP & $267.45 \pm 20.73$ & $259.44 \pm 17.70$ & $281.77 \pm 17.87$ & -34.43 & $<0.001^{b}$ \\
\hline LAP & $22.66(12.88,39.44)$ & $16.45(9.72,25.53)$ & $40.59(27.18,61.68)$ & -31.75 & $<0.001^{\mathrm{c}}$ \\
\hline WHtR & $48.87 \pm 4.90$ & $47.10 \pm 4.37$ & $52.02 \pm 4.15$ & -31.37 & $<0.001^{b}$ \\
\hline VAI & $1.34(0.85,2.14)$ & $1.05(0.72,1.54)$ & $2.08(1.37,3.25)$ & -19.14 & $<0.001^{\mathrm{c}}$ \\
\hline \multicolumn{6}{|c|}{$\begin{array}{l}\text { Data are mean } \pm \text { standard deviation or median (interquartile range) for continuous variables; } P \text { values present } \\
\text { comparisons between NAFLD patients and non-NAFLD subjects. }\end{array}$} \\
\hline \multicolumn{6}{|c|}{${ }^{\mathrm{a}}$ chi-squared test, ${ }^{\mathrm{b}}$ independent-samples $T$ test, ${ }^{\mathrm{c}}$ Mann-Whitney $\mathrm{U}$ test. } \\
\hline \multicolumn{6}{|c|}{$\begin{array}{l}\text { Abbreviations: NAFLD, nonalcoholic fatty liver disease; WC, waist circumference; BMI, body mass index; SBP, systolic } \\
\text { blood pressure; DBP, diastolic blood pressure; TC, total cholesterol; TG, triglyceride; TBIL, total bilirubin; DBIL, direct } \\
\text { bilirubinit HDL-C, high-density lipoprotein cholesterol; LDL-C, low-density lipoprotein cholesterol; ALT, alanine } \\
\text { aminotransferase; AST, aspartic transaminase; GGT, gamma-glutamyl transpeptidase; Scr, serum creatinine; FPG, } \\
\text { fasting plasma glucose; platelet count; FLI, fatty liver index; FLD, fatty liver disease index; ZJU, Zhejiang University } \\
\text { index; TyG, triglyceride and glucose index; CAP, controlled attenuation parameter; LAP, lipid accumulation product; } \\
\text { WHHtR, waist-to-height ratio; VAl, visceral adiposity index. }\end{array}$} \\
\hline
\end{tabular}

Table 3 provided the odd ratio (OR) of 1-unit increment of NAFLD-related models for mild, moderate and severe NAFLD. We calculated crude OR and adjusted OR (adjusted for age, sex, and BMI). Univariate and multivariate analyses showed that all of the eight models were positively associated with NAFLD (all $P<0.001$ ). In Table 4 and Fig. 1, ROC analysis results of NAFLD-related models for predicting NAFLD were presented. All of the models had a moderate discrimination in the overall, male and female population (all AUC $>0.75$, all $P<0.001$ ). Compared to total and male population, AUCs of all models were higher in female, and FLI $(0.897,0.875-0.917)$, FLD $(0.888,0.865-0.908)$ and ZJU $(0.892,0.869-$ $0.911)$ had a high AUC next to 0.9. The AUCs of FLI $(0.852,0.839-0.864)$, FLD $(0.852,0.839-0.864)$ were higher than other models to predict NAFLD in the overall population (Table 4, Fig. 2A). The results of comparison showed that the differences in FLI and FLD compared with ZJU were not significant in male and female population, and it was indicated that the AUC of FLI and FLD were higher than LAP, CAP, WHtR and TyG (all P<0.001) (Fig. 2B-2C). The Decision Curve Analysis showed that FLI, FLD and ZJU have higher net benefit to screen for NAFLD compared to other models (Fig. 3). 
Table 3

The odd ratios of one unit increment of NAFLD-related indexes for different degrees of NAFLD

\begin{tabular}{|c|c|c|c|c|c|c|}
\hline \multirow[t]{2}{*}{ Models } & \multicolumn{2}{|l|}{ Mild NAFLD } & \multicolumn{2}{|c|}{ Moderate NAFLD } & \multicolumn{2}{|l|}{ Severe NAFLD } \\
\hline & $\begin{array}{l}\text { OR } \\
(95 \% \mathrm{Cl})^{a}\end{array}$ & $\begin{array}{l}\text { Adjusted OR } \\
(95 \% \mathrm{Cl}) \text { a, b }\end{array}$ & OR $(95 \% \mathrm{Cl})^{a}$ & $\begin{array}{l}\text { Adjusted OR } \\
(95 \% \mathrm{Cl}) \text { a, b }\end{array}$ & OR $(95 \% \mathrm{Cl})^{a}$ & $\begin{array}{l}\text { Adjusted OR } \\
(95 \% \mathrm{Cl}) \text { a, b }\end{array}$ \\
\hline FLI & $\begin{array}{l}1.06(1.05, \\
1.07)\end{array}$ & $1.04(1.03,1.05)$ & $\begin{array}{l}1.09(1.08, \\
1.10)\end{array}$ & $1.08(1.07,1.10)$ & $\begin{array}{l}1.10(1.09 \\
1.12)\end{array}$ & $1.09(1.07,1.11)$ \\
\hline FLD & $\begin{array}{l}1.42(1.38, \\
1.47)\end{array}$ & $1.50(1.41,1.60)$ & $\begin{array}{l}1.74(1.66, \\
1.81)\end{array}$ & $2.10(1.94,2.29)$ & $\begin{array}{l}1.87(1.76, \\
2.00)\end{array}$ & $2.15(1.93,2.41)$ \\
\hline ZJU & $\begin{array}{l}1.42(1.38 \\
1.46)\end{array}$ & $1.44(1.36,1.52)$ & $\begin{array}{l}1.73(1.66, \\
1.81)\end{array}$ & $1.85(1.72,1.99)$ & $\begin{array}{l}1.85(1.74, \\
1.97)\end{array}$ & $1.89(1.72,2.07)$ \\
\hline LAP & $\begin{array}{l}1.05(1.05 \\
1.06)\end{array}$ & $1.03(1.02,1.03)$ & $\begin{array}{l}1.07(1.06, \\
1.07)\end{array}$ & $1.04(1.03,1.05)$ & $\begin{array}{l}1.07(1.06, \\
1.07)\end{array}$ & $1.04(1.03,1.05)$ \\
\hline CAP & $\begin{array}{l}1.07(1.06, \\
1.07)\end{array}$ & $1.09(1.06,1.12)$ & $\begin{array}{l}1.10(1.09, \\
1.11)\end{array}$ & $1.23(1.19,1.27)$ & $\begin{array}{l}1.12(1.11 \\
1.13)\end{array}$ & $1.24(1.19,1.30)$ \\
\hline WHtR & $\begin{array}{l}1.27(1.24, \\
1.30)\end{array}$ & $1.10(1.07,1.14)$ & $\begin{array}{l}1.41(1.36, \\
1.45)\end{array}$ & $1.19(1.14,1.25)$ & $\begin{array}{l}1.56(1.47 \\
1.65)\end{array}$ & $1.29(1.20,1.39)$ \\
\hline TyG & $\begin{array}{l}5.96(5.01, \\
7.08)\end{array}$ & $3.68(3.02,4.47)$ & $\begin{array}{l}12.56(9.90 \\
15.92)\end{array}$ & $\begin{array}{l}8.65(6.60 \\
11.35)\end{array}$ & $\begin{array}{l}14.62(10.23 \\
20.88)\end{array}$ & $\begin{array}{l}9.59(6.37 \\
14.45)\end{array}$ \\
\hline VAI & $\begin{array}{l}1.95(1.81 \\
2.11)\end{array}$ & $1.51(1.40,1.63)$ & $\begin{array}{l}2.24(2.06 \\
2.44)\end{array}$ & $1.72(1.58,1.87)$ & $\begin{array}{l}2.29 \\
(2.09,2.50)\end{array}$ & $1.76(1.60,1.92)$ \\
\hline \multicolumn{7}{|c|}{ a all $P<0.001 ;{ }^{b}$ adjusted for sex, age and $\mathrm{BMl}$; } \\
\hline \multicolumn{7}{|c|}{$\begin{array}{l}\text { Abbreviations: OR, odd ratio; NAFLD, nonalcoholic fatty liver disease; FLI, fatty liver index; FLD, fatty liver disease } \\
\text { index; ZJU, Zhejiang University index; TyG, triglyceride and glucose index; CAP, controlled attenuation parameter; LAP, } \\
\text { lipid accumulation product; WHtR, waist-to-height ratio; VAl, visceral adiposity index. }\end{array}$} \\
\hline
\end{tabular}

Table 4

Areas under receiver operating characteristics curves (AUC) of NAFLD-related models for predicting NAFLD

\begin{tabular}{|c|c|c|c|c|c|c|c|c|c|}
\hline \multirow[t]{2}{*}{ Models } & \multicolumn{3}{|l|}{ Total } & \multicolumn{3}{|l|}{ Male } & \multicolumn{3}{|c|}{ Female } \\
\hline & AUC & SE & $95 \% \mathrm{Cl}$ & AUC & SE & $95 \% \mathrm{Cl}$ & AUC & SE & $95 \% \mathrm{Cl}$ \\
\hline FLI & 0.852 & 0.01 & $0.839-0.864$ & 0.826 & 0.01 & $0.810-0.841$ & 0.897 & 0.01 & $0.875-0.917$ \\
\hline FLD & 0.852 & 0.01 & $0.839-0.864$ & 0.824 & 0.01 & $0.809-0.839$ & 0.888 & 0.01 & $0.865-0.908$ \\
\hline ZJU & 0.847 & 0.01 & $0.835-0.860$ & 0.826 & 0.01 & $0.810-0.841$ & 0.892 & 0.01 & $0.869-0.911$ \\
\hline LAP & 0.835 & 0.01 & $0.822-0.847$ & 0.804 & 0.01 & $0.788-0.820$ & 0.879 & 0.01 & $0.856-0.900$ \\
\hline CAP & 0.823 & 0.01 & $0.810-0.836$ & 0.794 & 0.01 & $0.778-0.810$ & 0.847 & 0.02 & $0.821-0.870$ \\
\hline WHtR & 0.797 & 0.01 & $0.783-0.811$ & 0.768 & 0.01 & $0.751-0.785$ & 0.812 & 0.02 & $0.784-0.837$ \\
\hline TyG & 0.792 & 0.01 & $0.777-0.806$ & 0.761 & 0.01 & $0.743-0.778$ & 0.834 & 0.02 & $0.807-0.859$ \\
\hline VAl & 0.791 & 0.01 & $0.777-0.805$ & 0.769 & 0.01 & $0.751-0.786$ & 0.837 & 0.02 & $0.810-0.861$ \\
\hline
\end{tabular}




\section{Cut-off values of models for the detection of NAFLD}

The optimal cut-off values were determined by the maximum of Youden index. The sensitivity and specificity of NAFLDrelated models at the optimal cut-off values were displayed in Table 5. FLI > 20.6 (sensitivity $=85.3 \%$ and specificity = $75.1 \%$ ) was the optimal cut-off point of NAFLD screening in total population. In male and female population, the cut-off values were different $(25.3$, sensitivity $=78.4 \%$ and specificity $=72.4 \% ; 8.4$, sensitivity $=88.1 \%$ and specificity $=78.2 \%$ ). The cut-off points of FLD were $>28.7$ (sensitivity $=79.6 \%$ and specificity $=75.2 \%$ ) in whole population, $>29.0$ (sensitivity $=80.0 \%$ and specificity $=70.0 \%$ ) in male population, $>26.1$ (sensitivity $=88.2 \%$ and specificity $=75.6 \%$ ) in female population. ZJU had the same cut-off point (> 33.7) in all population.

Table 5

Optimal cut-off values and diagnostic accuracy of NAFLD-related models in total, male and female population

\begin{tabular}{|c|c|c|c|c|c|c|c|c|c|}
\hline \multirow[t]{2}{*}{ Model } & \multicolumn{3}{|l|}{ Total } & \multicolumn{3}{|l|}{ Male } & \multicolumn{2}{|c|}{ Female } & \multirow[b]{2}{*}{$\begin{array}{l}\text { Specificity } \\
(\%)\end{array}$} \\
\hline & $\begin{array}{l}\text { Cut- } \\
\text { off }^{a}\end{array}$ & $\begin{array}{l}\text { Sensitivity } \\
(\%)\end{array}$ & $\begin{array}{l}\text { Specificity } \\
(\%)\end{array}$ & $\begin{array}{l}\text { Cut- } \\
\text { off }^{a}\end{array}$ & $\begin{array}{l}\text { Sensitivity } \\
\text { (\%) }\end{array}$ & $\begin{array}{l}\text { Specificity } \\
(\%)\end{array}$ & $\begin{array}{l}\text { Cut- } \\
\text { off }^{a}\end{array}$ & $\begin{array}{l}\text { Sensitivity } \\
\text { (\%) }\end{array}$ & \\
\hline FLI & 20.6 & 85.3 & 75.1 & 25.3 & 78.4 & 72.4 & 8.4 & 88.1 & 78.2 \\
\hline FLD & 28.7 & 79.6 & 75.2 & 29.0 & 80.0 & 70.0 & 26.1 & 88.2 & 75.6 \\
\hline ZJU & 33.7 & 80.6 & 73.8 & 33.7 & 80.4 & 69.3 & 33.7 & 82.6 & 82.3 \\
\hline LAP & 26.9 & 75.6 & 77.7 & 26.9 & 77.3 & 71.1 & 19.7 & 84.4 & 77.9 \\
\hline CAP & 269.7 & 75 & 74.2 & 272.4 & 72.2 & 71.6 & 259.9 & 79.5 & 77.1 \\
\hline WHtR & 49.7 & 72.5 & 72.5 & 49.4 & 76.6 & 63.6 & 45.5 & 91.9 & 56.3 \\
\hline TyG & 9.1 & 71.9 & 73.1 & 9.1 & 72.5 & 67.7 & 8.9 & 70.2 & 82.1 \\
\hline VAI & 1.6 & 68.3 & 76.1 & 1.7 & 62.9 & 78.3 & 1.6 & 71.2 & 81.8 \\
\hline \multicolumn{10}{|c|}{${ }^{a}$ Cut-off values were determined by the maximum of Youden index. } \\
\hline $\begin{array}{l}\text { Abbrev } \\
\text { Zhejiar } \\
\text { accum }\end{array}$ & $\begin{array}{l}\text { tions: N } \\
\text { Univers } \\
\text { ation pr }\end{array}$ & $\begin{array}{l}\text { LD, nonalcc } \\
\text { index; TyG } \\
\text { uct; WHtR, }\end{array}$ & $\begin{array}{l}\text { olic fatty liv } \\
\text { iglyceride a } \\
\text { ist-to-heigh }\end{array}$ & $\begin{array}{l}\text { diseas } \\
\text { gluco } \\
\text { atio; V }\end{array}$ & $\begin{array}{l}\text { FLI, fatty live } \\
\text { index; CAP, c } \\
\text { visceral adip }\end{array}$ & $\begin{array}{l}\text { index; FLD, } \\
\text { ontrolled atte } \\
\text { ssity index. }\end{array}$ & $\begin{array}{l}\text { atty liver } \\
\text { uation }\end{array}$ & $\begin{array}{l}\text { lisease inde) } \\
\text { arameter; LA }\end{array}$ & ZJuU, \\
\hline
\end{tabular}

\section{Discussion}

More than a dozen models have been proposed to detect NAFLD patients, and most of them had a good diagnostic performance in the original study such as the Steato Test [22], FLI [10], FLD index [14], Hepatic steatosis index (HSI) [23], Framingham steatosis index (FSI) [24], homeostasis model assessment of insulin resistance (HOMA-IR) [25], and index of NASH (ION) [26]. However, some indicators in these models are costly and not available in most laboratories in the undeveloped countries, such as a2-macroglobulin, apolipoprotein A-I in the Steato Test, and the insulin test in HOMA-IR and ION. In order to determine a simple, accurate and cost-effective model for NAFLD screening on a large scale, we screened out NAFLD-related models developed by simple indicators. We validated eight NAFLD-related models (FLI, FLD, ZJU, LAP, CAP, WHtR, TyG and VAI) and compared the performance of these models in eastern Chinese community population. Our study showed that all of these models have a moderate discrimination, and FLI and FLD have better performance than other models in this population.

FLI, consisting of TG, GGT, BMI and WC, was developed by Bedogni et al [10] in northern Italy, 2006. It has been validated to a great extent and has been proved to be correlated with insulin resistance, coronary heart disease, and 
early atherosclerosis $[27,28]$. Studies have shown that FLI has a moderate discrimination (AUC, 0.83-0.88) in Taiwan, northern and western Chinese mainland $[17,29,30]$. Our study has testified the feasibility of FLI in eastern Chinese mainland and proved that FLI has good applicability in the community population. FLD based on BMI, TG, ALT to AST ratio and FPG was proposed by Fuyan et al. in eastern China with an AUC of 0.82 [14]. It has been validated by Jinzhou et al. recently with an AUC of 0.87 in western China, but it was no better than FLI (AUC, 0.88) [29]. Our study supported that FLD has the same diagnostic performance as FLI. Besides, the Decision Curve Analysis also suggested that FLI and FLD have higher net benefit than other models. The population in Jinzhou et al.'s study was western Chinese while our population was eastern Chinese, which can cause a great difference.

ZJU also has a great performance in this study but it doesn't perform as well as FLD in the whole population. ZJU was developed based on BMI, FPG, TG, ALT to AST ratio and gender with an AUC of 0.82 in eastern China, and in the validation cohort using pathological data, the ZJU index had a good accuracy (AUC, 0.896) for the detection of steatosis [15]. Some recent studies have validated ZJU and compared to other models including FLI using large population, with conflicting results $[29,31]$. The underlying reason may be the difference of NAFLD prevalence and characteristics of population.

LAP, CAP, WHtR, TyG and VAl in our study have AUCs of over 0.75 in all population. WC as a good surrogate parameter of visceral fat [32,33], is the common component of FLI, LAP, WHtR and VAI. Visceral adiposity has a significant association with increased free fatty acids, which can be transported to liver and expose the liver to fat accumulation, liver insulin resistance and inflammation [34]. CAP was developed based on 141 histological diagnosed NAFLD patients and has higher accuracy than FibroScan [16]. The sample size in the primary study may be too small to develop a model applying to general population. To our knowledge, CAP has not been external validated. TyG has a strong correlation with the degree of NAFLD, but the AUC of TyG to detect NAFLD is not in parallel with the high risk correlation. TyG has been used to reflect insulin resistance, which is very important in the development of NAFLD [35]. Apart from insulin resistance, transaminases and anthropometric indicators also play vital roles in the prediction of NAFLD. It may be the reason why the diagnostic performance of TyG is not in line with the relationship to NAFLD, and is not as well as FLI and FLD.

Cut-off value is an important concern when applying models to specific population. We also determined cut-off values of these models in this population. The cut-off values of FLI and FLD differ in gender and are inconsistent with previous studies. The optimal cut-off points of the FLI in the present study were 20.6, 25.3 and 8.4 in the total, male and female population respectively. Western countries mostly identified $\mathrm{FLI}<30$ as non-NAFLD and $>60$ as NAFLD without gender difference [10]. Li C et al. determined the optimal cut-off point of FLI as 20 in the north Chinese population, which was similar to our findings [30]. But they didn't detect the gender difference of the cut-off values. A validation study of FLI in Taiwan also showed lower cut-off values for NAFLD than Western populations [17]. Body size, body composition and fat distribution have difference among different races and ethnic groups due to the environment, nutrition factors and culture [36, 37], which leads to the diversity of anthropometric and serological measurements. Women had higher percent of fat mass, extremity fat, and lower lean mass compared to men at the same level of age and BMI [38]. This may explain the lower cut-off values in female subjects. The optimal cut-off values of FLD in different population are more stable (28.7, 29.0 and 26.1 for total, male and female respectively) than FLI, while the cut-off value for female subjects is also lower than male. So it is essential to apply corresponding cut-off values among different population.

Our results showed that FLI and FLD can be used to screen for NAFLD in eastern Chinese community population. The expenditure of these models in eastern China has not been studied. Jinzhou et al. compared the expenditure of several NAFLD-related models in western China [29]. FLI costs 20 Yuan per capita, which is lower than FLD and ZJU. So FLI may have advantages in expenditure and accessibility compared to other models. The cost-effectiveness of these models should be further studied. 
The strength of this study includes large scale population, comprehensive analysis of the variables and head to head comparison of included models. There are also some limitations in our study. Ultrasonography as a diagnostic method for NAFLD has limited sensitivity [39]. But ultrasound is a preferable method for large scale screening of asymptomatic individuals like community population. Another limitation is we didn't adjust for other factors such as physical activity, diet and smoke, which may have correlation with the risk of metabolic symptoms. Additionally, our study was retrospective, further prospective studies are needed to evaluate the applied values of these models.

\section{Conclusions}

In conclusion, we validated and compared eight NAFLD-related models for noninvasive diagnosis of NAFLD in eastern Chinese community population. FLI and FLD are more accurate and applicable in our study. The cut-off values should be used according to gender. The cost-effectiveness of NAFLD-related models should be further evaluated.

\section{Abbreviations}

NAFLD: Nonalcoholic fatty liver disease; FLI: Fatty liver index; FLD: Fatty liver disease index; ZJU: Zhejiang University index; LAP: Lipid accumulation product; CAP: Regression formula of controlled attenuation parameter; WHtR: Waist-toheight ratio; TyG: Triglyceride and glucose index; VAl: Visceral adiposity index; FPG: Fasting plasma glucose; TG: triglycerides; TC: total cholesterol; HDL-C: high-density lipoprotein cholesterol; LDL-C: low-density lipoprotein cholesterol; ALT: alanine aminotransferase; AST: aspartate aminotransferase; GGT: y-glutamyl transferase

\section{Declarations}

\section{Ethics approval and consent to participate}

All procedures followed were in accordance with the ethical standards of the responsible committee on human experimentation (institutional and national) and with the Helsinki Declaration of 1975, as revised in 2008. Informed consent was obtained from all patients for being included in the study. This study does not contain any studies with animals performed by the authors.

\section{Consent for publication}

All authors of the study consent to publish the results.

\section{Availability of data and materials}

All data in the study will be available if requested.

\section{Competing interests}

The authors declare that they have no competing interest.

\section{Funding}

This work was supported in part by Natural Science Foundation of Jiangsu Province (grant no. BK20181369), the Six Talent Peak Project in Jiangsu Province (grant no. 2019-WSN-049), and Priority Academic Program Development of Jiangsu Higher Education Institutions (grant no. PAPD, [2018] 87).

\section{Authors' contributions}


LZ: study design, data collection, statistical analysis, manuscript preparation. MW: data collection, statistical analysis, manuscript preparation, literature search. MXW: data collection, statistical analysis, manuscript preparation, literature search. RZ: data collection, statistical analysis. HLW: data collection. WZ: study design. YJD: manuscript preparation, literature search. JW: study design, funds collection. All authors revised and approved the final manuscript.

\section{Acknowledgements}

We thank all doctors and nurses who dedicated to the data collection and kind suggestions.

\section{Authors' information}

${ }^{1}$ Department of Fundamental and Community Nursing, School of Nursing, Nanjing Medical University, Nanjing, China (No. 101 Longmian Avenue, Jiangning District, Nanjing 211166, Jiangsu, China)

${ }^{2}$ Mofan West Road Community Health Service Center, Nanjing, China (No.3 Dinghuaimen, Gulou District, Nanjing 210013, China)

${ }^{3}$ Department of Epidemiology, Shanghai Cancer Institute, Shanghai, China (No. 25, Lane 2200, Xietu Road, Shanghai 200032, China)

\section{References}

1. Younossi Z, Anstee QM, Marietti M, Hardy T, Henry L, Eslam M, et al. Global burden of NAFLD and NASH: trends, predictions, risk factors and prevention. Nat Rev Gastroenterol Hepatol. 2018;15:11-20.

2. Ji YX, Huang Z, Yang X, Wang X, Zhao LP, Wang PX, et al. The deubiquitinating enzyme cylindromatosis mitigates nonalcoholic steatohepatitis. Nat Med. 2018;24:213-23.

3. Younossi ZM, Blissett D, Blissett R, Henry L, Stepanova M, Younossi Y, et al. The economic and clinical burden of nonalcoholic fatty liver disease in the United States and Europe. Hepatology. 2016;64:1577-86.

4. Perumpail BJ, Khan MA, Yoo ER, Cholankeril G, Kim D, Ahmed A. Clinical epidemiology and disease burden of nonalcoholic fatty liver disease. World J Gastroenterol. 2017;23:8263-76.

5. Zhang XJ, She ZG, Li H. Time to step-up the fight against NAFLD. Hepatology. 2018;67:2068-71.

6. Rockey DC, Caldwell SH, Goodman ZD, Nelson RC, Smith AD. Diseases CAftSoL. Liver biopsy. Hepatology. 2009;49:1017-44.

7. Duarte-Rojo A, Altamirano JT, Feld JJ. Noninvasive markers of fibrosis: key concepts for improving accuracy in daily clinical practice. Ann Hepatol. 2012;11:426-39.

8. Castera L, Friedrich-Rust M, Loomba R. Noninvasive Assessment of Liver Disease in Patients With Nonalcoholic Fatty Liver Disease. Gastroenterology. 2019;156:1264-81.e4.

9. Lee JS, Aoki K, Kawakubo K, Gunji A. A study on indices of body fat distribution for screening for obesity. Sangyo Eiseigaku Zasshi. 1995;37:9-18.

10. Bedogni G, Bellentani S, Miglioli L, Masutti F, Passalacqua M, Castiglione A, et al. The Fatty Liver Index: a simple and accurate predictor of hepatic steatosis in the general population. BMC Gastroenterol. 2006;6:33.

11. Simental-Mendía LE, Rodríguez-Morán M, Guerrero-Romero F. The product of fasting glucose and triglycerides as surrogate for identifying insulin resistance in apparently healthy subjects. Metab Syndr Relat Disord. 2008;6:299304.

12. Bedogni G, Kahn HS, Bellentani S, Tiribelli C. A simple index of lipid overaccumulation is a good marker of liver steatosis. BMC Gastroenterol. 2010;10:98. 
13. Petta S, Amato MC, Di MV, Cammà C, Pizzolanti G, Barcellona MR, et al. Visceral adiposity index is associated with significant fibrosis in patients with non-alcoholic fatty liver disease. Aliment Pharmacol Ther. 2012;35:238-47.

14. Fuyan S, Jing L, Wenjun C, Zhijun T, Weijing M, Suzhen W, et al. Fatty liver disease index: a simple screening tool to facilitate diagnosis of nonalcoholic fatty liver disease in the Chinese population. Dig Dis Sci. 2013;58:3326-34.

15. Wang J, Xu C, Xun Y, Lu Z, Shi J, Yu C, et al. ZJU index: a novel model for predicting nonalcoholic fatty liver disease in a Chinese population. Sci Rep. 2015;5:16494.

16. Feng G, He N, Zhou YF, Li XP, Niu C, Liu ML, et al. A simpler diagnostic formula for screening nonalcoholic fatty liver disease. Clin Biochem. 2019;64:18-23.

17. Yang BL, Wu WC, Fang KC, Wang YC, Huo TI, Huang YH, et al. External validation of fatty liver index for identifying ultrasonographic fatty liver in a large-scale cross-sectional study in Taiwan. PLoS ONE. 2015;10:e0120443.

18. Vanni E, Bugianesi E. Editorial: utility and pitfalls of Fatty Liver Index in epidemiologic studies for the diagnosis of NAFLD. Aliment Pharmacol Ther. 2015;41:406-7.

19. Jian-gao F, Association CLD. Guidelines for management of nonalcoholic fatty liver disease: an updated and revised edition. Zhonghua Gan Zang Bing Za Zhi. 2010;18:163-6.

20. CollectiveName:National Workshop on Fatty Liver and Alcoholic Liver Disease CSoH. Association CM. CollectiveName:Fatty Liver Expert Committee CMDA: [Guidelines of prevention and treatment for nonalcoholic fatty liver disease: a 2018 update]. Zhonghua Gan Zang Bing Za Zhi. 2018; 26:195-203.

21. DeLong ER, DeLong DM, Clarke-Pearson DL. Comparing the areas under two or more correlated receiver operating characteristic curves: a nonparametric approach. Biometrics. 1988;44:837-45.

22. Poynard T, Ratziu V, Naveau S, Thabut D, Charlotte F, Messous D, et al. The diagnostic value of biomarkers (SteatoTest) for the prediction of liver steatosis. Comp Hepatol. 2005;4:10.

23. Lee JH, Kim D, Kim HJ, Lee CH, Yang Jl, Kim W, et al. Hepatic steatosis index: a simple screening tool reflecting nonalcoholic fatty liver disease. Dig Liver Dis. 2010;42:503-8.

24. Long MT, Pedley A, Colantonio LD, Massaro JM, Hoffmann U, Muntner P, et al. Development and Validation of the Framingham Steatosis Index to Identify Persons With Hepatic Steatosis. Clin Gastroenterol Hepatol. 2016;14:117280.e2.

25. Matthews DR, Hosker JP, Rudenski AS, Naylor BA, Treacher DF, Turner RC. Homeostasis model assessment: insulin resistance and beta-cell function from fasting plasma glucose and insulin concentrations in man. Diabetologia. 1985;28:412-9.

26. Otgonsuren M, Estep MJ, Hossain N, Younossi E, Frost S, Henry L, et al. Single non-invasive model to diagnose nonalcoholic fatty liver disease (NAFLD) and non-alcoholic steatohepatitis (NASH). J Gastroenterol Hepatol. 2014;29:2006-13.

27. Gastaldelli A, Kozakova M, Højlund K, Flyvbjerg A, Favuzzi A, Mitrakou A, et al. Fatty liver is associated with insulin resistance, risk of coronary heart disease, and early atherosclerosis in a large European population. Hepatology. 2009;49:1537-44.

28. Kim D, Choi SY, Park EH, Lee W, Kang JH, Kim W, et al. Nonalcoholic fatty liver disease is associated with coronary artery calcification. Hepatology. 2012;56:605-13.

29. Zhu J, He M, Zhang Y, Li T, Liu Y, Xu Z, et al. Validation of simple indexes for nonalcoholic fatty liver disease in western China: a retrospective cross-sectional study. Endocr J. 2018;65:373-81.

30. Li C, Guo P, Zhang R, Zhang M, Li Y, Huang M, et al. Both WHR and FLI as Better Algorithms for Both Lean and Overweight/Obese NAFLD in a Chinese Population. J Clin Gastroenterol. 2019;53:e253-3e260. 
31. Li L, You W, Ren W. The ZJU index is a powerful index for identifying NAFLD in the general Chinese population. Acta Diabetol. 2017;54:905-11.

32. CPS P, ADS D, IKG A, APDL L, MMV P, Rodrigues IG. Waist circumference measurement sites and their association with visceral and subcutaneous fat and cardiometabolic abnormalities. Arch Endocrinol Metab. 2018;62:416-23.

33. Fang H, Berg E, Cheng X, Shen W. How to best assess abdominal obesity. Curr Opin Clin Nutr Metab Care. 2018;21:360-5.

34. Tchernof A, Després JP. Pathophysiology of human visceral obesity: an update. Physiol Rev. 2013;93:359-404.

35. Gastaldelli A. Insulin resistance and reduced metabolic flexibility: cause or consequence of NAFLD. Clin Sci. 2017;131:2701-4.

36. Khalil SF, Mohktar MS, Ibrahim F. The theory and fundamentals of bioimpedance analysis in clinical status monitoring and diagnosis of diseases. Sensors (Basel). 2014;14:10895-928.

37. Rush EC, Freitas I, Plank LD. Body size, body composition and fat distribution: comparative analysis of European, Maori, Pacific Island and Asian Indian adults. Br J Nutr. 2009;102:632-41.

38. Schorr M, Dichtel LE, Gerweck AV, Valera RD, Torriani M, Miller KK, et al. Sex differences in body composition and association with cardiometabolic risk. Biol Sex Differ. 2018;9:28.

39. Fishbein M, Castro F, Cheruku S, Jain S, Webb B, Gleason T, et al. Hepatic MRI for fat quantitation: its relationship to fat morphology, diagnosis, and ultrasound. J Clin Gastroenterol. 2005;39:619-25.

\section{Figures}

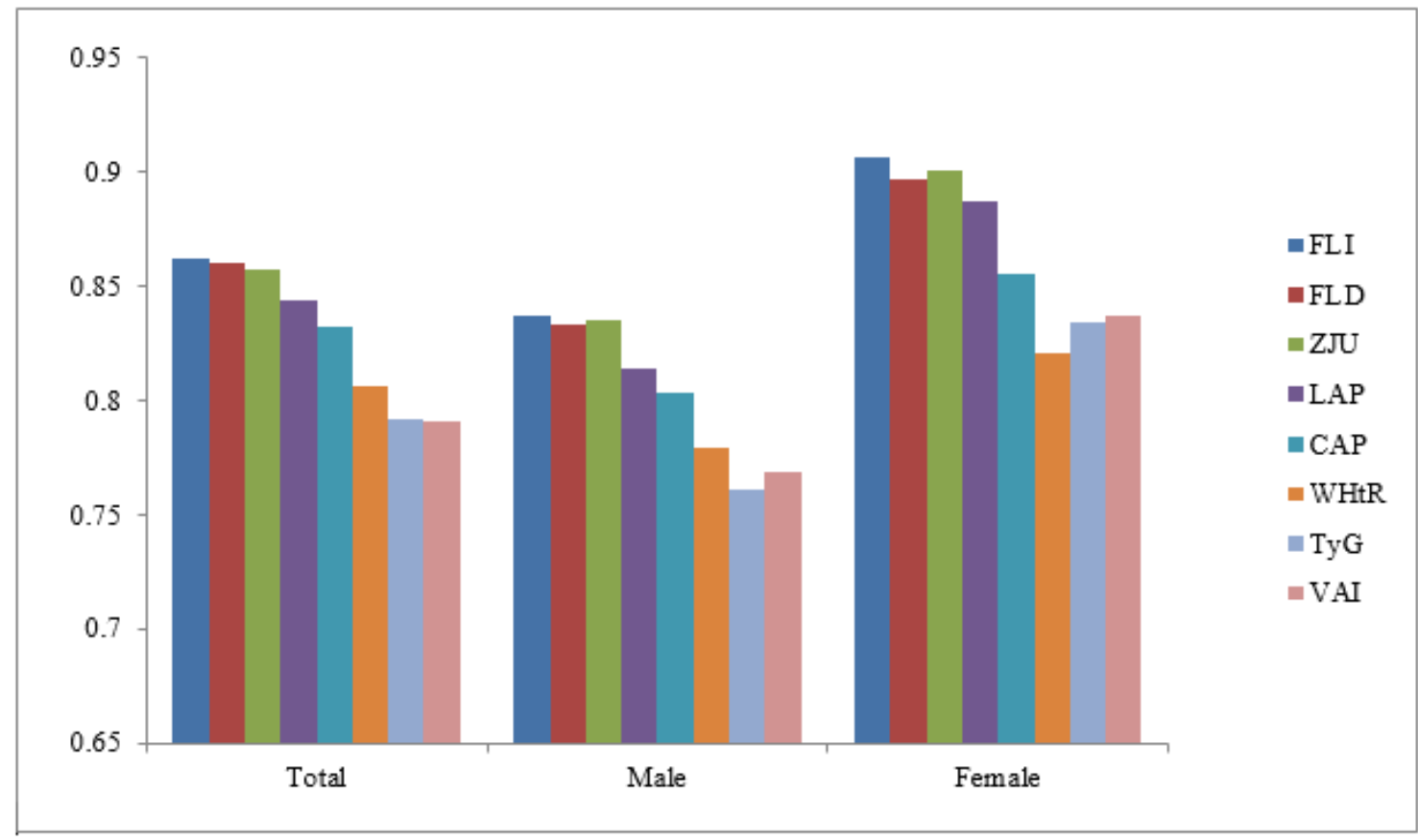

\section{Figure 1}

Areas under receiver operating characteristic (AUC) curves of NAFLD-related models in total, male and female.

Abbreviations: NAFLD, nonalcoholic fatty liver disease; FLI, fatty liver index; FLD, fatty liver disease index; ZJU, Zhejiang University index; TyG, triglyceride and glucose index; CAP, controlled attenuation parameter; LAP, lipid accumulation product; WHtR, waist-to-height ratio; VAl, visceral adiposity index. 


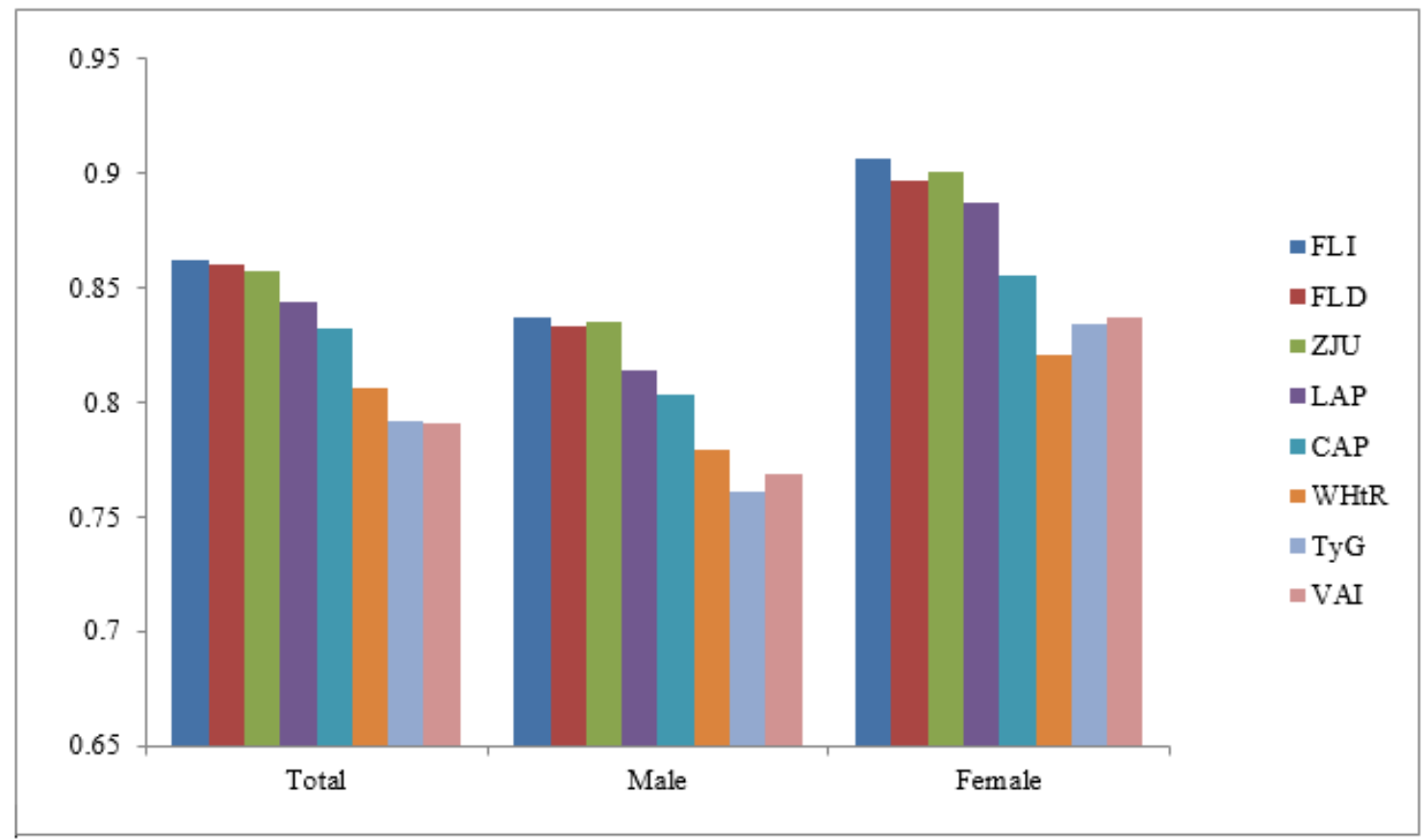

\section{Figure 1}

Areas under receiver operating characteristic (AUC) curves of NAFLD-related models in total, male and female.

Abbreviations: NAFLD, nonalcoholic fatty liver disease; FLI, fatty liver index; FLD, fatty liver disease index; ZJU, Zhejiang University index; TyG, triglyceride and glucose index; CAP, controlled attenuation parameter; LAP, lipid accumulation product; WHtR, waist-to-height ratio; VAl, visceral adiposity index. 
A. Comparison of ROC curves in total population

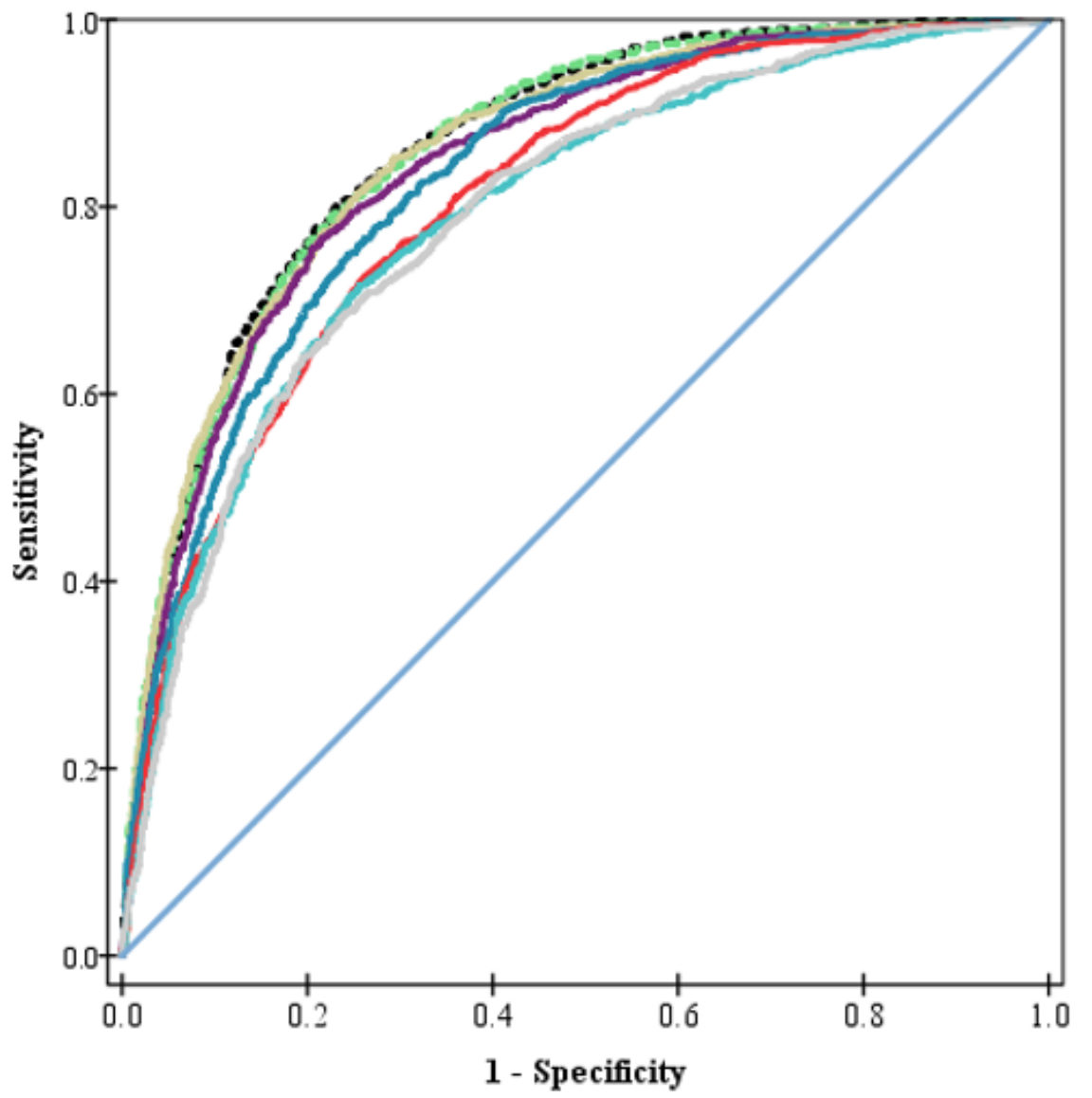

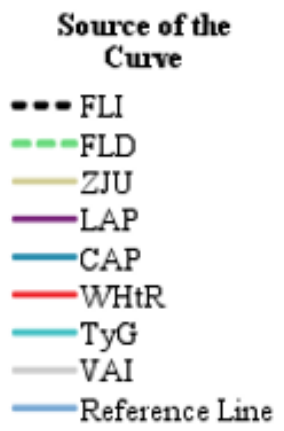

FLI vs. FLD,$P=0.97$;

FLI vs. ZJU, $P=0.34$;

FLD vs. ZJU, $P=0.04$;

FLI vs. LAP; CAP; WHtR;

TyG; VAI, all $P<0.001$;

FLD vs. LAP; CAP; WHtR;

TyG; VAI, all $P<0.001$.

\section{Figure 2}

Comparison of Receiver-operating characteristic (ROC) curves of the NAFLD-related models for the detection of NAFLD. A. Comparison of ROCs in total population. B. Comparison of ROCs in male population. C. Comparison of ROCs in female population. Comparisons of the areas under receiver operating characteristic (AUC) curves between FLI and other indexes were performed by the method of DeLong et al. Abbreviations: NAFLD, nonalcoholic fatty liver disease; FLI, fatty liver index; FLD, fatty liver disease index; ZJU, Zhejiang University index; TyG, triglyceride and glucose index; CAP, controlled attenuation parameter; LAP, lipid accumulation product; WHtR, waist-to-height ratio; VAl, visceral adiposity index. 
A. Comparison of ROC curves in total population

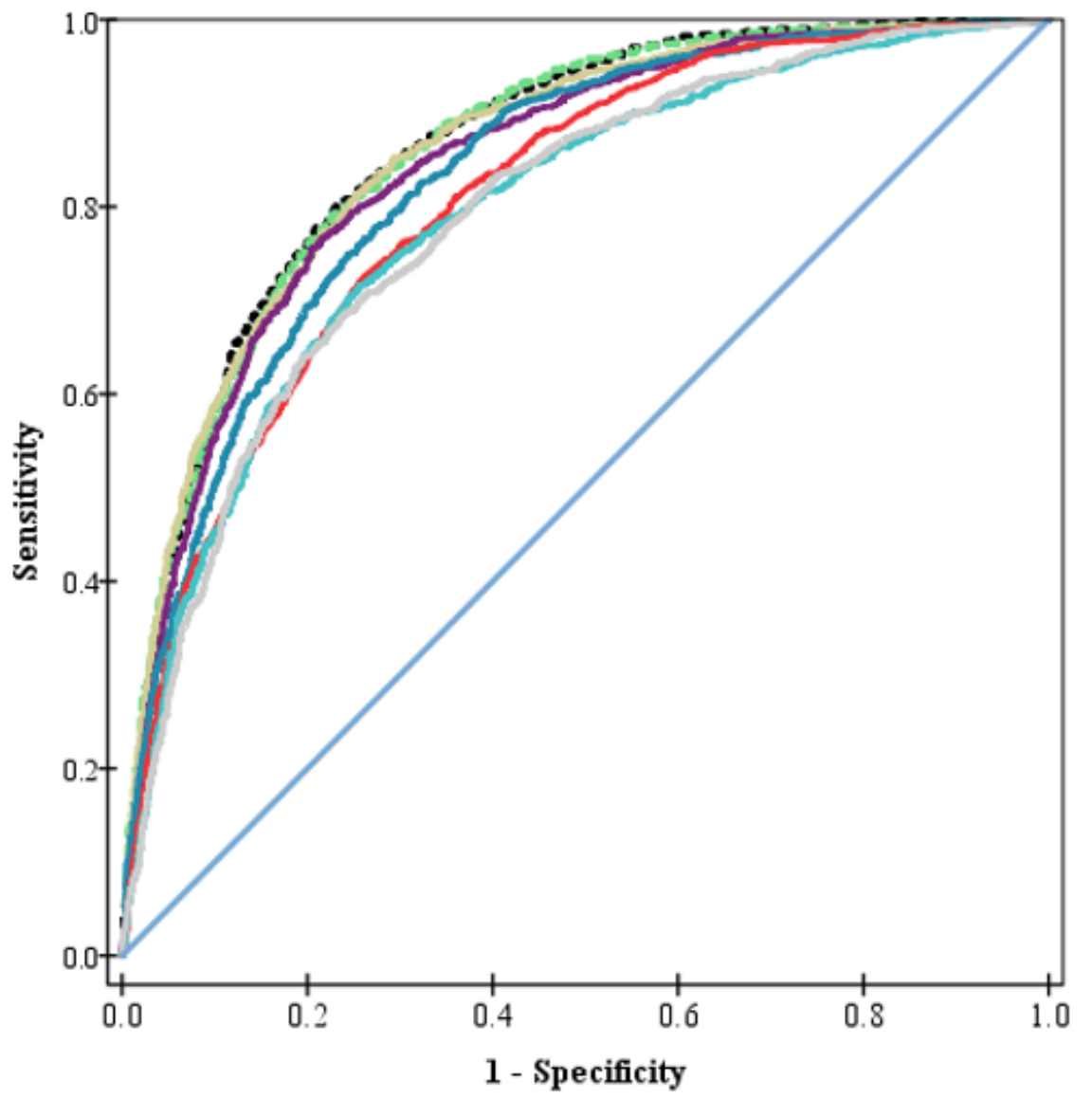

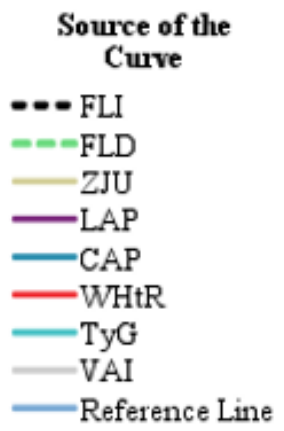

FLI vs. FLD,$P=0.97$;

FLI vs. ZJU, $P=0.34$;

FLD vs. ZJU, $P=0.04$;

FLI vs. LAP; CAP; WHtR;

TyG; VAI, all $P<0.001$;

FLD vs. LAP; CAP; WHtR;

TyG; VAI, all $P<0.001$.

\section{Figure 2}

Comparison of Receiver-operating characteristic (ROC) curves of the NAFLD-related models for the detection of NAFLD. A. Comparison of ROCs in total population. B. Comparison of ROCs in male population. C. Comparison of ROCs in female population. Comparisons of the areas under receiver operating characteristic (AUC) curves between FLI and other indexes were performed by the method of DeLong et al. Abbreviations: NAFLD, nonalcoholic fatty liver disease; FLI, fatty liver index; FLD, fatty liver disease index; ZJU, Zhejiang University index; TyG, triglyceride and glucose index; CAP, controlled attenuation parameter; LAP, lipid accumulation product; WHtR, waist-to-height ratio; VAl, visceral adiposity index. 


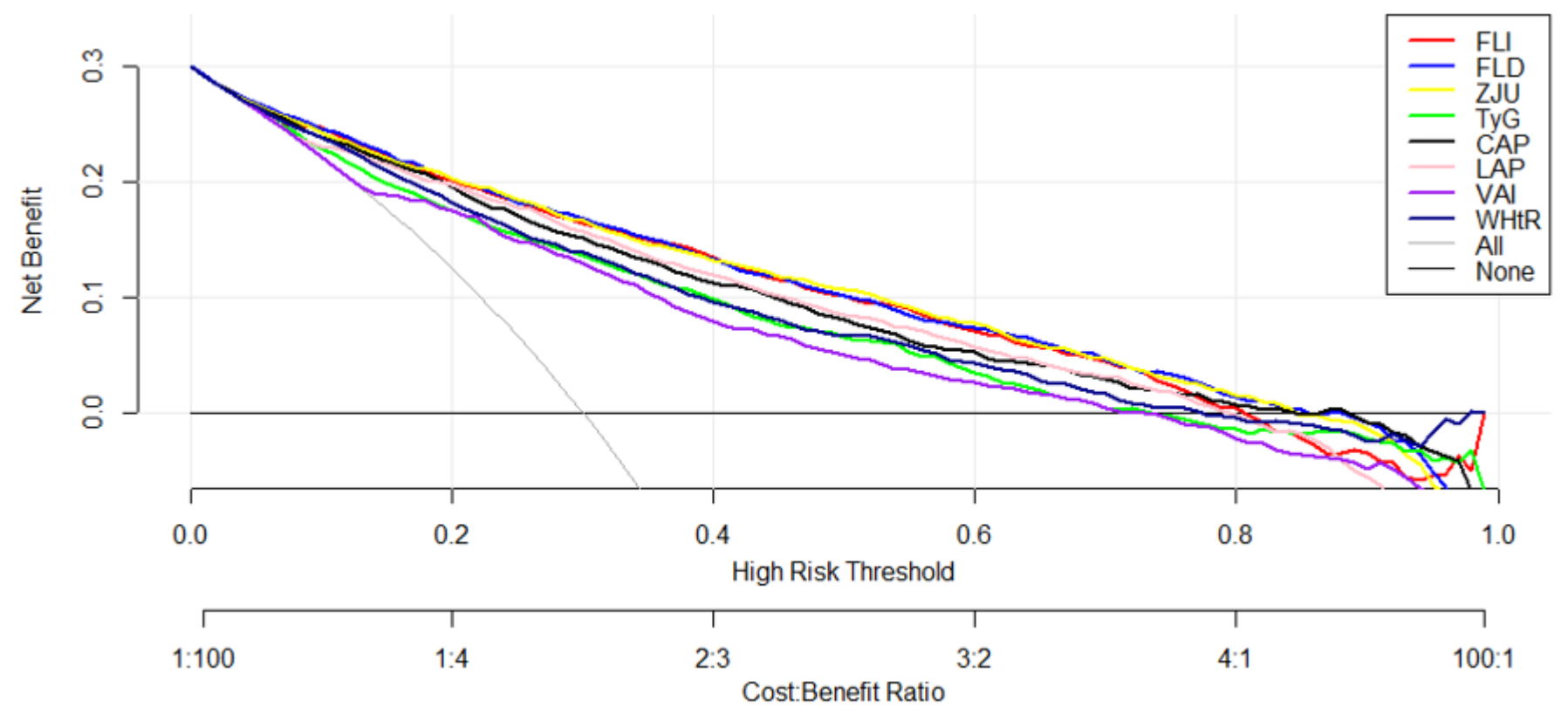

Figure 3

Decision Curve Analysis for nonalcoholic fatty liver disease Screening. Abbreviations: NAFLD, nonalcoholic fatty liver disease; FLI, fatty liver index; FLD, fatty liver disease index; ZJU, Zhejiang University index; TyG, triglyceride and glucose index; CAP, controlled attenuation parameter; LAP, lipid accumulation product; WHtR, waist-to-height ratio; VAl, visceral adiposity index.

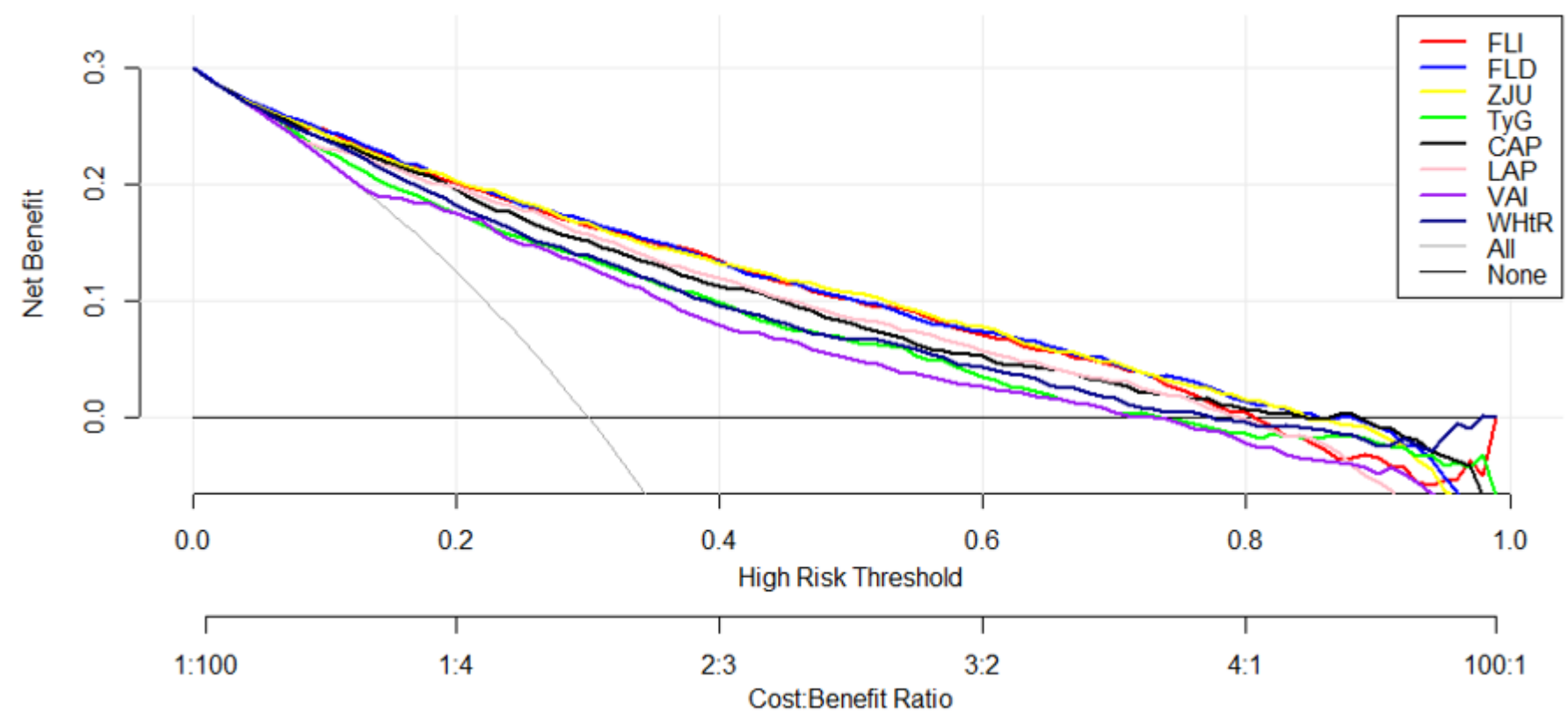

Figure 3

Decision Curve Analysis for nonalcoholic fatty liver disease Screening. Abbreviations: NAFLD, nonalcoholic fatty liver disease; FLI, fatty liver index; FLD, fatty liver disease index; ZJU, Zhejiang University index; TyG, triglyceride and glucose index; CAP, controlled attenuation parameter; LAP, lipid accumulation product; WHtR, waist-to-height ratio; VAl, visceral adiposity index. 